\title{
Knowledge and Practice of Iodized Salt and Iodine Deficiency Disorders among Men in Nungua, Ghana
}

\author{
Jacob Setorglo ${ }^{1, *}$, Philip Narteh Gorleku ${ }^{2}$, Frederick Sarpong ${ }^{3}$, Christiana Buxton ${ }^{1}$, \\ Francisca Naana Arthur ${ }^{4}$, Bismark Anin Agyei ${ }^{5}$, Matilda Steiner-Asiedu ${ }^{5}$ \\ ${ }^{1}$ Department of Clinical Nutrition and Dietetics, University of Cape Coast, Ghana \\ ${ }^{2}$ Department of Imaging Sciences, University of Cape Coast, Ghana \\ ${ }^{3}$ School of Food and Biological and Engineering, Jiangsu University, China \\ ${ }^{4}$ Department of Community Health, College of Health, Ghana \\ ${ }^{5}$ Department of Nutrition and Food Science, University of Ghana, Ghana
}

Received October 22, 2019; Revised March 31, 2020; Accepted April 19, 2020

Copyright $\mathrm{C} 2020$ by authors, all rights reserved. Authors agree that this article remains permanently open access under the terms of the Creative Commons Attribution License 4.0 International License

\begin{abstract}
Background: Iodine Deficiency Disorders (IDDs) continues to be a problem in Ghana after several years of salt fortification with iodine. Sustainable IDDs prevention requires a well-informed population and their willingness to use iodized salt. This study determined the levels of knowledge of men on iodized salt, IDDs iodized salt usage. Methods: This was a cross-sectional study involving 400 men (18 years and above) sampled conveniently at Nungua in the Ledzokuku Krowor Municipality of the Greater Accra Region, Ghana. Data on socio-demographics, knowledge, use of iodized salt and IDDs were collected. We computed descriptive statistics for socio-demographic data, knowledge of iodized salt, usage of iodized salt and knowledge on IDDs. We grouped scores for knowledge on iodized salt into poor and good. Scores for knowledge on IDDs were split into tertiles and labeled as low, moderate, and high. Chi-Square $\left(\chi^{2}\right)$ test and multinomial logistic regression were performed to determine the association between socio-demographic characteristics, good knowledge on iodized salt and high knowledge about IDDs. Results: Majority of respondents (37.5\%) were aged between 26 and 41 years. About $97.8 \%$ have heard about iodized salt and $69.3 \%$ first heard about iodized salt through the media. About $70.5 \%$ used iodized salt in cooking and $76.8 \%$ of the respondents would encourage women to use salt in cooking. When knowledge level was split into two groups, the higher proportion (266 out of 400) had poor knowledge on iodized salt and in tertiles, the majority (184 of 400) had low knowledge on IDDs. There were statistically significant differences between age, marital status and educational level and knowledge on IDDs all at $\mathrm{P}<0.001$. Those with Junior High School education had 54\% less chance, $\mathrm{OR}=0.465$; $95 \%$ CI: $(0.244,0.884)$ of obtaining good knowledge on
\end{abstract}

iodized salt compared with those who had University education. Conclusions: Knowledge on iodized salt was low, and knowledge on IDDs was low among the men. There is a difference in the level of knowledge of IDDs among the socio-economic groups but not knowledge on iodized salt and its use. The more educated the men are, the more likely they are to use iodized salt.

Keywords Iodine Deficiency Disorders, Iodized Salt, Ghana, Knowledge, Men

\section{Introduction}

The World Health Organization (WHO) estimated that about two billion individuals in 118 countries worldwide have insufficient iodine intake $[1 ; 2 ; 3]$. The WHO and the United Nations Children Fund (UNICEF) have recommended Universal Salt Iodization (USI) to ensure sufficient intake of iodine by all individuals, and seeks to achieve at least $90 \%$ of household consumption of adequately iodized salt [3; 4]. In Ghana, Universal Salt Iodization (USI) programme was launched in 1995, with legal backing by Act 523 of 1996, and was aimed at $90 \%$ household consumption of iodized salt by the end of 2005 [5;6]. However, a recent study indicated that Ghana had not achieved the USI of $90 \%$ consumption of iodized salt by households [2]. There has also been marginal increases in household consumption of adequately iodized salt from $28 \%$ to about $39 \%$ between 2003 and 2014 in over a decade [7] since USI implementation. Iodine deficiency disorders (IDDs) is of significant importance in public health 
globally [8]. Iodine Deficiency Disorders (IDDs) are endemic in $51.8 \%$ of Ghana's 216 districts [9;10]. It has been projected that 1.5 million children will suffer from mild to severe irreversible brain damage due to iodine deficiency between the period of 2011 to 2020 [11]. Currently, only $39 \%$ of Ghanaian households are consuming adequately iodized salt [7]. Multiple Indicator Cluster Survey (MICS) (2010-2011) found that there was a difference in levels of household iodized salt consumption. Nearly one in four $(24 \%)$ households used salt that was not iodized [11]. Nine out of 10 districts in Ghana have less than half of households that consumed iodized salt [7] and almost half of Ghanaian households (42\%) used salt that was not iodized [5]. Studies conducted in Ghana to assess why the country had not attained USI revealed mixed results [4; 7]. In Ghana, men as household heads were generally responsible for providing finances for food and its ingredients and therefore their knowledge on the use of iodized salt and IDDs are important to the use of iodized salt [7]. Despite the implementation of USI and strategies to ensure individuals use iodized salt for food, low iodized salt usage and iodine deficiency disorders (IDDs) continue to exist in Ghana [7]. Awareness of iodized salt (81.7\%) was higher than awareness of iodine deficiency $(40.2 \%)$ nationally. Household coverage for salt with any iodine was $61.9 \%$ [7]. Despite the returns associated with improved nutritional health due to iodized salt consumption, there is no iodized consumption and knowledge data among men in an urban area in Ghana. A study by Ahiadeke et al. has shown that the choice of using iodized salt is a function of the knowledge of the potential benefits [12]. Consequence of nutrient deficiency, such as stunting as a leading post-Millennium Development Goal $[13 ; 14]$. Micronutrient strategies for the elimination of nutritional malnutrition is being examined. There is the need to examine the evidence to support policy $[15 ; 16]$. There The prevention and correction of iodine deficiency may be an important contributor to reducing stunting which is high among Ghanaian children under five years. Ghana is a patrilineal country where men are the household heads and therefore decides what foods the household eats and what types of ingredients they use in the food preparation. To continually use the views of women to drive policy on USI is not sufficient and may have accounted for the low usage of iodized salt since the strategies were developed and implemented. This accounted for the reason why we decided to sought the views of men alone in this study. Nungua is a very patrilineal society where men make input into food system. Therefore, this cross-sectional study on men (household heads) was undertaken in Nungua, a paternalistic community to assess their level of knowledge on iodized salt, its use, knowledge on IDDs and the associated socio-demographic factors.

\section{Participants and Methods}

\subsection{Study Area}

The study was carried out at Nungua, in the Ledzokuku Krowor Municipality (LEKMA) of the Greater Accra Region of Ghana. Nungua is the administrative capital of the Ledzokuku Krowor municipal Assembly. The total land area of LEKMA is estimated at 47.57510 square kilometers. The Southern boundary of the Municipality is the Gulf of Guinea from the Kpeshie Lagoon to the Mukwe Lagoon near Regional Maritime Academy. The population of Ledzokuku Krowor Municipality is 227,932 representing 5.7 percent of the region's total population [7]. Males constitute 47.9 percent, and females represent 52.1 percent. The municipality has a household population of 221,757 with a total number of 60,859 households. The average household size in the municipality is 3.6 persons [7].

\subsection{Study Design}

This was a quantitative cross-sectional study.

\subsection{Sample Size and Sampling Procedure}

We calculated sample size based on the formula of Gorstein et al. [17]. The formula yielded a sample size of 384 male respondents. This number was however rounded up to 400 to increase the precision of the estimates and account for any incomplete data that may result from the data collection exercise. Earlier studies on knowledge of iodized salt use in Ghana had about the same number of respondents $[6,7]$. A sample of 400 men were selected conveniently at the Nungua township. We adopted two types of sampling procedures for recruiting potential respondents at the workplace and within the community. Two hundred respondents each were sampled from the community and workplaces. At the community, a bottle was spun to determine the direction to proceed in sampling the houses and then the households with the household heads. A maximum of eight houses were sampled from each direction since the communities are small, after which the bottle was spun at the same spot for a new direction. This was repeated until the sample size was achieved. Regarding the sampling at the workplaces, a list of public and private organizations in Nungua was collected form the municipal assembly. Six of the organization in the Nungua township was purposively selected. Weighting was used to determine the number of workers to sample from each organization. Systematic sampling was used to recruit respondents irrespective of position within the organizational structure. 


\subsection{Instruments}

Validated questionnaires were pretested and later administered to participants in their homes and workplaces by in-person interviews. The questionnaire contained items that were used in similar studies in South Africa [18] and Ethiopia [19]. Face and content validities were ensured by getting feedback from an expert in iodine study at the Nutrition Unit of the Ministry of Health, Ghana and also piloting the questionnaire on a sample of men at Teshie which have similar socio-economic characteristics like Nungua and the lineage is the same. The questions were on three main parts; socio-demographics status, knowledge on iodized salt usage and knowledge on IDDs. The socio-demographic characteristics were on their ages (years), highest level of educational attainment, ethnicity, religious affiliation and marital status. On knowledge on iodized salt, the questions were: if you have heard about iodized salt, where they first heard about iodized salt, it was important to use iodized salt for cooking, whether every salt on the market contain iodine? Whether common salt contains an adequate amount of iodine? Whether the taste of iodized salt different from taste of common salt when used to prepare food. Information was sought on the use of iodized salt and these were: whether respondent cooked own food, the person responsible for your cooking use iodized salt in cooking, duration of iodized salt use, How often do respondent use iodized salt, if iodized salt always available at home for cooking, if salt change the flavor/taste of food, respondent would encourage women to use iodized salt in cooking. Knowledge on IDDs was sought by asking the following questions on presence: of goiter, lack of energy, dry skin, frequent tiredness, low blood level (anemia), sluggishness, low blood level and sleeplessness among adults.

\subsection{Data Collection Procedure}

The questionnaire was pre-tested on four men for appropriateness and clarity of the questions to solicit appropriate responses from the respondents. Edits were made to the logic of the items on the questionnaire. After this, questionnaires were administered on participants by trained interviewers either at home or their workplaces. Questions were asked in the local language (Ga) or English language depending on language proficiency and preference of the respondents.

\subsection{Quality Control}

Quality of the data to be collected was ensured through training of the interviewers on the study protocol and the use of instruction manual for the interviews for two days at the University of Ghana resource center. There was also supervision and monitoring of the data collection process, spot checking during field interviews and field editing of completed questionnaires. Regarding reliability, the supervisor sampled completed questionnaires and went back to administer a new questionnaire and compare responses with the previously filled questionnaire by the research attendant. Cronbach's alpha for the test items on the questionnaire was 0.81 .

\subsection{Data Analysis}

Data was coded, entered and analyzed using IBM Statistical Package for the Social Sciences (SPSS version 19, SPSS Inc., Chicago, Illinois, USA). Descriptive statistics were computed for socio-demographic data, knowledge on iodized salt and IDDs. Percentages were presented for knowledge on IDDs among adults. For a correct response to a question on knowledge, the respondent scores a point and for an incorrect answer there was no point. Scores for knowledge on iodized salt were grouped into poor knowledge ( $\leq 4$ points) and good knowledge ( $>4$ points). Scores for knowledge on IDDs were split into tertiles and labeled as low ( $\leq 2$ points), moderate knowledge (3-6 points) and high ( $\geq 7$ points). Scores for the levels of knowledge of iodized salt were also split into two groups based on participants' responses. Chi-Square $\left(\chi^{2}\right)$ test and multinomial logistic regression were performed to determine the association between socio-demographic characteristics, knowledge on iodized salt and knowledge about IDDs, and predictors of good knowledge about iodized salt and high knowledge about IDDs.

\subsection{Ethical Considerations}

The approval for the study was given by the Scientific and Ethical Committee of the Department of Nutrition and Food Science, University of Ghana, Legon. Permission was sought from the municipal assembly where the research took place. Signed informed consents were sought from every participant before recruitment into the study. Details of the study were read out to participants in their preferred language. Respondents were made aware that, participation was voluntary and they could withdraw at any stage. Confidentiality was assured and soft copies of data was stored on the cloud, secured with a password while hard copies were stored in a secured cupboard at the Principal investigator's office.

\section{Results}

\subsection{Background Characteristics and Knowledge of Participants on Iodized Salt}

This section presents results on the background characteristics and knowledge on iodized salt by 400 respondents. Majority (37.5\%) of respondents were aged between 26 and 41 years, and $37.0 \%$ had attained SHS/Vocational/Commercial educational level (Table 1). 
More than half (58.8\%) were either single/divorced/unmarried (Table 1). Most have heard about iodized (97.8\%) and majority (69.3\%) first heard about iodized salt through the media. About $79.8 \%$ of respondents (agreed that it was important to use iodized salt to cook, although more than half $(52.0 \%)$ said iodized salt tastes different from non-iodized salt.

Table 1. Background characteristics and knowledge of participants on salt $(\mathrm{N}=400)$

\begin{tabular}{|l|l|}
\hline Age (years) & $\mathrm{n}(\%)$ \\
\hline$\leq 25$ & $145(36.3)$ \\
\hline $26-41$ & $150(37.5)$ \\
\hline$\geq 42$ & $105(26.2)$ \\
\hline Highest Level of education attainment & \\
\hline$\leq$ Primary & $37(9.3)$ \\
\hline Up to JHS & $100(25.0)$ \\
\hline SHS/Vocational/Commercial & $148(37.0)$ \\
\hline Polytechnic/University & $115(28.7)$ \\
\hline Marital status & \\
\hline Single/Divorced/Widowed & $235(58.8)$ \\
\hline Married/Cohabiting & $165(41.2)$ \\
\hline Have you heard about iodized salt? & \\
\hline Yes & $391(97.8)$ \\
\hline No & $9(2.2)$ \\
\hline Where first did you hear about iodized salt? & \\
\hline Media & $277(69.3)$ \\
\hline Health workers & $18(4.5)$ \\
\hline Friends & $17(4.2)$ \\
\hline Own child & $6(1.5)$ \\
\hline Others & $82(20.5)$ \\
\hline Is it important to use iodized salt in cooking? & \\
\hline Yes & $319(79.8)$ \\
\hline No & $57(14.2)$ \\
\hline Don't know & $24(6.0)$ \\
\hline Do every salt contains iodine? & \\
\hline Yes & $2108(52)$ \\
\hline No & $98(24.5)$ \\
\hline Don't know & $242(60.5)$ \\
\hline Adequate iodine in common salt. & $60(15)$ \\
\hline Yes & \\
\hline No & $11(27.75)$ \\
\hline Don't know & \\
\hline Taste of iodized salt different from taste of common $)$ \\
\hline Yas & \\
\hline No & \\
\hline Don't know & \\
\hline
\end{tabular}

\subsection{Participants' Use of Iodized Salt}

Since knowledge on salt was high among respondents, their use of iodized salt at home in food preparation was examined and responses presented (Table 2). About 70.5\% used iodized salt in cooking, and $52.0 \%$ have used iodized salt for 10 years. About half of respondents (51.5\%) used iodized salt every day and $63.0 \%$ have iodized salt at home always for cooking. Less than half (46.5\%) indicated that iodized salt change the flavor/taste of food when added to food. A large proportion of respondents $(76.8 \%)$ would encourage women to use iodized salt in cooking.

Table 2. Participants' use of iodized salt $(\mathrm{N}=400)$

\begin{tabular}{|l|l|}
\hline Variable & $\mathrm{n}(\%)$ \\
\hline Do you cook your own food? & \\
\hline Yes & $188(47.0)$ \\
\hline No & $212(53.0)$ \\
\hline $\begin{array}{l}\text { Do you or the person responsible for your cooking } \\
\text { use iodized salt in cooking? }\end{array}$ & \\
\hline Yes & $282(70.5)$ \\
\hline No & $81(20.3)$ \\
\hline Don't know & $37(9.2)$ \\
\hline How long have you been using iodized salt? & \\
\hline$\leq 5$ years & $79(28.0)$ \\
\hline $6-10$ years & $79(28.0)$ \\
\hline $11-15$ years & $30(10.7)$ \\
\hline$\geq 16$ years & $33(11.7)$ \\
\hline Don't remember & $61(21.6)$ \\
\hline How often do you use iodized salt? & \\
\hline Everyday & $206(51.5)$ \\
\hline$\leq 4$ times a week & $62(15.5)$ \\
\hline Once a month & $32(8.0)$ \\
\hline Once in a while & $100(25.0)$ \\
\hline $\begin{array}{l}\text { Is iodized salt always available at home for } \\
\text { cooking }\end{array}$ & $80(20.0)$ \\
\hline Yes & $13(3.2)$ \\
\hline No & $252(63.0)$ \\
\hline Don't know & $129(32.2)$ \\
\hline Does iodized salt change the flavor/taste of food & $19(4.8)$ \\
\hline Yes & $186(46.5)$ \\
\hline No & $132(33.0)$ \\
\hline Don't know & $820.5)$ \\
\hline \begin{tabular}{l} 
Would you encourage women to use iodized salt \\
\hline Yes
\end{tabular} \\
\hline No & \\
\hline Don't know & \\
\hline ipping to & \\
\hline
\end{tabular}

${ }^{1}$ Applies to the participants who used iodized salt

\subsection{Participants' Knowledge about Effects of Non-Use of Iodized Salt on Adults}

The IDDs knowledge among the participants are presented in Figure 1. Majority (38.4\%) indicated that iodine deficiency can result in goiter but $13.1 \%$ of the men also do not know whether lack of iodine in the body can result in any IDDs. Lack of energy was indicated by $9.8 \%$ of the respondents. 


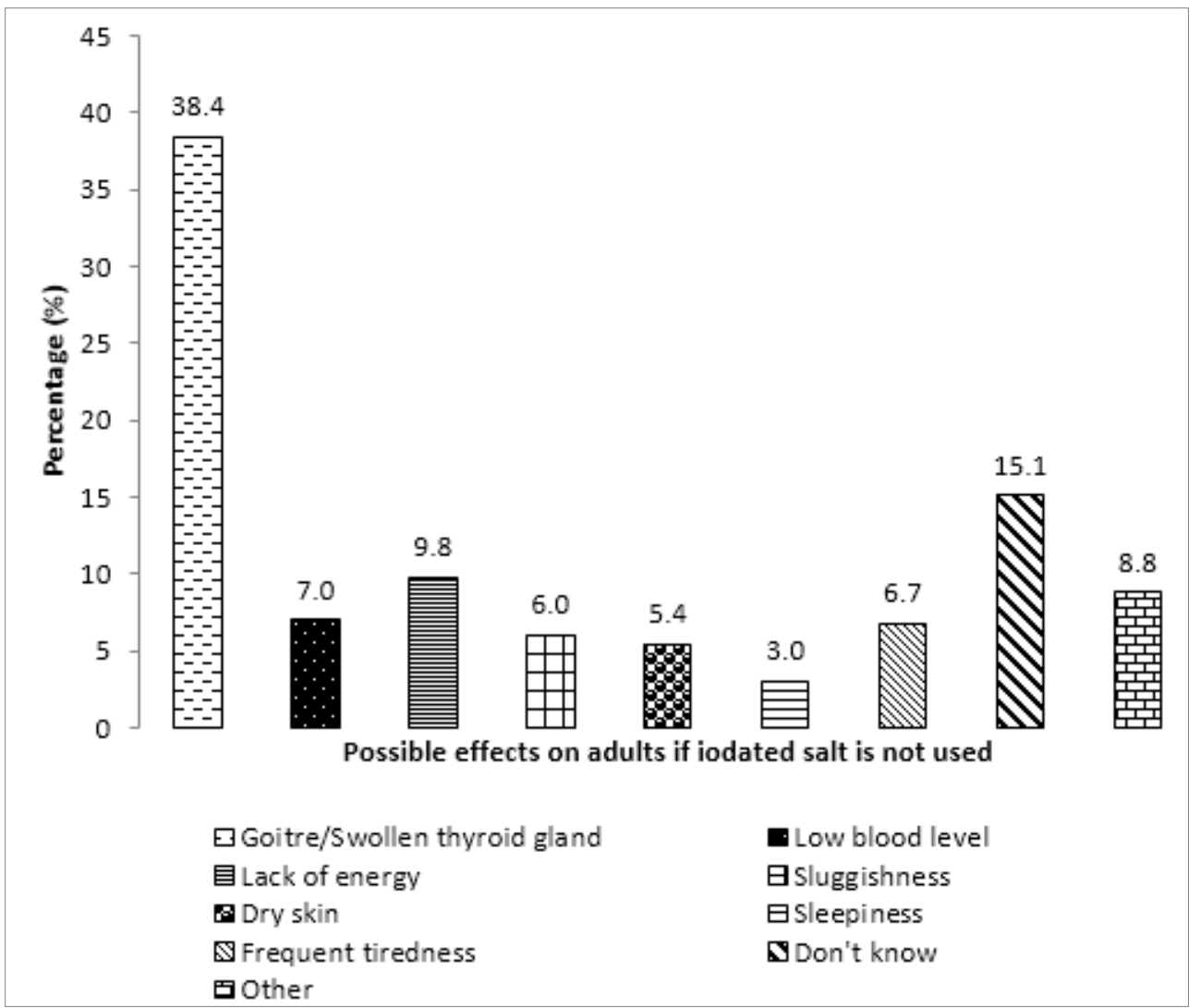

Figure 1. Percentage distribution of participants' knowledge about effects of non-use of iodized salt on adults.

\subsection{Socio-Demographic Characteristics by Knowledge of Iodized Salt and IDDs}

Associations between socio-demographic characteristics and knowledge of iodized salt (poor and good) socio-demographic and Knowledge of IDDs (low, moderate and high) were tested using Chi-square test (Table 3). Majority had poor knowledge (266) on iodized salt. Majority also had low knowledge on IDDs (184). The socio-demographic characteristics did not have any statistically significant associations with the level of knowledge of iodized salt. There were statistically significant differences in the knowledge of IDDs between the age groups $(\mathrm{P}<0.001)$, level of education $(\mathrm{P}<0.001)$ and marital status $(\mathrm{P}<0.001)$.

Table 3. Socio-demographic characteristics by knowledge of iodized salt and IDD ( $N=400)$

\begin{tabular}{|c|c|c|c|c|c|c|c|}
\hline & \multicolumn{2}{|l|}{ Knowledge of iodized. salt } & \multicolumn{3}{l}{ Knowledge of IDDs } \\
\hline & Poor & Good & & Low & Moderate & High & \\
\hline Variable & $\mathrm{n}=266 \dagger$ & $\mathrm{n}=134 \dagger$ & P-value. & $\mathrm{n}=184 \dagger$ & $\mathrm{n}=102 \dagger$ & $\mathrm{n}=114 \dagger$ & P-value. \\
\hline Age (years) & & & & & & & \\
\hline$\leq 25$ & $96(36.1)$ & $49(36.6)$ & 0.861 & $49(26.6)$ & $52(51.0)$ & $40(35.1)$ & $<0.001 \dagger$ \\
\hline $26-41$ & $102(38.3)$ & $48(35.8)$ & & $69(37.5)$ & $39(38.2)$ & $51(44.7)$ & \\
\hline$\geq 42$ & $68(25.6)$ & $37(27.6)$ & & $66(35.9)$ & $11(10.8)$. & $23(20.2)$ & \\
\hline Level of education* & & & & & & & \\
\hline$\leq$ Primary & $20(7.5)$ & $17(12.7)$ & 0.370 & $29(15.8)$ & $2(2.0)$ & $6(5.3)$ & $<0.001$ \\
\hline JHS & $70(26.3)$ & $30(22.4)$ & & $60(32.6)$ & $21(20.6)$ & $19(16.7)$ & \\
\hline SHS/Vocational/ Commercial & $99(37.2)$ & $49(36.6)$ & & $63(34.2)$ & $34(33.3)$ & $51(44.7)$ & \\
\hline University/Polytechnic & $77(28.9)$ & $38(28.4)$ & & $32(17.4)$ & $45(44.1)$ & $38(33.3)$ & \\
\hline Marital Status & & & & & & & \\
\hline Married/ Cohabiting & $155(58.3)$ & $80(59.7)$ & 0.830 & $92(50.0)$ & $75(73.5)$ & $68(59.6)$ & $<0.001$ \\
\hline Single/Widowed/ Divorced & $111(41.7)$ & $54(40.3)$ & & $92(50.0)$ & $27(26.5)$ & $46(40.4)$ & \\
\hline
\end{tabular}

$\ddagger$ Significant at $\mathrm{P}<0.05$; $†$ Values in columns are $\mathrm{n}(\%) ; * J H S=$ Junior High School, SHS= Senior High School 


\subsection{Multinomial Logistic Regression Results of Factors That Predicted Good Knowledge of Iodized Salt and High Knowledge of IDDs}

The predictors of good knowledge of iodized salt and high knowledge of IDDs were determined using a multinomial logistic regression (Table 4). The odds of having high knowledge on IDDs were not statistically significant among the selected socio-demographic characteristics. The odds for having good knowledge on iodized salt was statistically significant less for those who had JHS compared with those who had university education $\mathrm{OR}=0.465$; $\mathrm{CI}:(0.244,0.884)$ at $\mathrm{P}<0.020$.

Table 4. Multinomial logistic regression results of factors that predicted good knowledge of iodized salt and high knowledge of IDDs $(\mathrm{N}=400)$ Write the method section and include this.

\begin{tabular}{|c|c|c|c|}
\hline \multicolumn{4}{|l|}{ High knowledge of IDDs } \\
\hline Variable & OR & $95 \% \mathrm{CI}$ & P-value \\
\hline \multicolumn{4}{|l|}{ Age (years) } \\
\hline$\leq 25$ & 0.924 & $(0.471,1.815)$ & 0.819 \\
\hline $26-41$ & 0.856 & $(0.483,1.520)$ & 0.596 \\
\hline$* \geq 42$ & 1.000 & & \\
\hline \multicolumn{4}{|l|}{ Level of education. } \\
\hline$\leq$ Primary & 1.715 & $(0.787,3.737)$ & 0.175 \\
\hline JHS & 0.860 & $(0.478,1.548)$ & 0.615 \\
\hline SHS/Vocational/ Commercial & 0.981 & $(0.582,1.655)$ & 0.943 \\
\hline University/Polytechnic & 1.000 & & \\
\hline \multicolumn{4}{|l|}{ Marital Status } \\
\hline Married/ Cohabiting & 1.130 & $(0.661,1.930)$ & 0.655 \\
\hline Single/Widowed/ Divorced & 1.000 & & \\
\hline \multicolumn{4}{|l|}{ Good knowledge of salt } \\
\hline Variable & OR & $95 \% \mathrm{CI}$ & P-value \\
\hline \multicolumn{4}{|l|}{ Age (years) } \\
\hline$\leq 25$ & 1.105 & $(0.531,2.299)$ & 0.789 \\
\hline $26-41$ & 0.968 & $(0.521,1.799)$ & 0.919 \\
\hline$\geq 42$ & 1.000 & & \\
\hline \multicolumn{4}{|l|}{ Level of education\# } \\
\hline$\leq$ Primary & 0.386 & $(0.145,1.026)$ & 0.056 \\
\hline JHS & 0.465 & $(0.244,0.884)$ & 0.0201 \\
\hline SHS/Vocational/ Commercial & 1.064 & $(0.631,1.792)$ & 0.817 \\
\hline University/Polytechnic & 1.000 & & \\
\hline \multicolumn{4}{|l|}{ Marital Status } \\
\hline Married/ Cohabiting & 0.856 & $(0.480,1.526)$ & 0.589 \\
\hline Single/Widowed/ Divorced & 1.000 & & \\
\hline
\end{tabular}

*=reference value; \#JSH= Junior High School, SHS= Senior High School

As women are more actively involved in the process of cooking, their knowledge and practice should also be assessed. This could also be addressed in the limitations of the study. This was indicated as a limitation of the study, but all data on knowledge on knowledge were on women. We compared the findings on the men with the data on women in Ghana. The results indicated that the majority of the participants were unmarried. The findings should be compared with the marital status of the population. In case of difference in the distribution patterns, the sample assessed might not be the representative of the population in the region. Marital status was not part of the inclusion criteria for this study. We therefore did not understand how this would affect the representativeness of the findings. There was a reason which we indicated in our discussion.

\section{Discussion}

The knowledge of respondents on iodized salt and Iodine Deficiency Disorders (IDDs) were assessed among 400 men in Nungua, a suburb of Accra, Ghana. Knowledge on iodized salt was poor, and most men also had low knowledge on IDDs. This compares contrarily to previous studies in Ghana on women that indicated that knowledge on iodized salt was high [6]. The disparity may be due to the fact that women were targeted in the messages on iodized salt compared with women. Probably the poor knowledge on iodized salt and the low knowledge on IDDs by men have been a contributory factor in not achieving USI in the area. In a patrilineal society, a decision such as including use of iodized salt would have to be approved by the men who are the household heads and also provides the funds for purchase of household items including food ingredients. Men, however, can serve as advocates within the households since majority have heard about iodized salt (Table1) [5]. The news media and health workers were the main source of information on iodized salt. These findings were consistent with that by [20] and Ahiadeke et al. [12] and [11]. Previous studies on iodized salt usage in Ghana, views on women were usually sampled ignoring those of the men who are the household heads and actually have a say in the type of salt that should be used in the cooking. It is equally important to note that, a little less than half of the respondents $(47 \%)$ of respondents cook their own food Table 2. They would also encourage household member preparing food to use iodized salt in cooking food for the family. The proportion is higher than $28 \%$ in 2003 and 39\% of females in 2014 and may suggest continued upward trend in iodized salt usage [7]. Having heard of iodized salt translated into availability and consumption of iodized salt (Table 2). The few who did not use iodized salt for cooking may be due to the change in taste or flavour when iodized salt is used in food preparation and compares well with an earlier study [11]. It may also be due to non-enforcement of the law that regulates iodized salt production and use since there are still non-iodized salts being sold on the market and are cheaper [6;7] than iodized salt [21]. Others believe that consumption of iodized salt can lead to the development of some strokes and cancers [6]. There may be constructs in the health behavior of respondents that 
were not assessed here, which may also account for the non-translation of knowledge to use. Perceptions about potential benefits and dangers may be associated with a certain behavior which are illustrated in the health belief model [22]. The low level of educational attainment of respondents had a direct association with good knowledge as determined in this study, where knowledge among Junior High School (JHS) graduates was lower compared with University graduates (Table 4). This probably suggests that messages, on radio which is the main avenue for dissemination of information on knowledge, are not advocated in ways that are comprehensible to the segment of the population that do not higher educational status to understand. This can be shored up through information transmission in the local dialect and also conveying messages to JHS in the Municipality $[6 ; 12]$. The greater percentage of men compared with previous study reported they had iodized salt at home always (Table 2). This was contrary to the findings of Ahiadeke et al. [12] where 32\% of Ghanaian households had available iodized salt. Greater number $235(58.8 \%)$ of respondents were either single/divorced. This suggested that they cook their own meals and therefore their knowledge on the use of iodized salt would influence their behaviors when it comes to iodized salt usage. When this number eventually gets a spouse, this knowledge is likely to be transferred to them. Indeed, $70 \%$ of respondents cook own food and $76.8 \%$ would recommend use of iodized salt to women. It was known that residents of Volta, Eastern, Northern and Upper East regions mostly use non-iodized salt, while people living in the Western, Greater Accra (a suburb of which this study took place), Ashanti and Brong Ahafo regions used relatively greater amount of iodized salt [6]. Majority of the respondents were not married. There were statistically significant differences in the level of knowledge of IDDs among the socio-demographic and the selected socio-demographic characteristics (age, marital status and educational level) Table 3. Marital status differences may be attributed to misconception that use of iodized salt may lead to infertility [23]. Age differences in the use of iodized salt may be attributed to misconception as well, since an earlier study found that chronic disease among older people are attributed to use of iodized salt [23]. Older respondents may be reluctant to use iodized salt in food preparation. Results in this study shows clearly the differences in the knowledge variables among men. It was found in a study in western Ghana where the people are mostly farmers and suggested that the use of public health personnel in the dissemination of information in the local languages $[6 ; 12]$. A study by Sandaresan et al. found the similar results [24]. Education helps give understanding to messages on iodized salt [25]. One limitation of the study was that, the authors did not explore the access of iodized salt at Nungua. This was because in a patrilineal community, men do not access food ingredients including salt of any form. Another, limitation of the study was not assessing the knowledge of the women in the household but the findings of the men were compared with earlier studies on women which can be generalized. In addition, not all the men sampled were married and the knowledge of their spouses could be sought. In Ghana, men are the head of households, and their lifestyle choices affect the health of members. In Ghana, they estimated that 120,000 children born each year are at risk of intellectual impairment because of iodine deficiency [12]. Therefore, assessment of knowledge and use is a monitoring process that gives policy-makers feedback on USI and status, knowledge and level of use of iodized salt.

\section{Implications for Health Promotion}

Men should be used as advocates on iodized salt use in the house and also education on the health consequences on iodine deficiency. Tailored messages on IDDs should target the different socio-demographic groupings such that messages on IDDs will be received and interpreted across the various socio-demographic groups the same way. This can be done through schools, churches and mosques. There should be monitoring and enforcement of legislation on USI so that there will be no non- iodized salt on the market for consumer purchase and use. On the other hand, there should be readily available iodized salt at affordable prices. There should be national and sub-national committees to provide practical and effective mechanisms to sustain commitments to IDDs elimination, since the laws alone are not enough to compel households to use iodized salt.

\section{Conclusions}

Awareness on iodized salt among the men was high. The knowledge on iodized salt was low, and the knowledge on IDDs was low among the men. There is a difference in the level of knowledge of IDDs among the socio-economic groups but not knowledge on iodized salt and it's use. The more educated the men are, the more likely they are to use iodized salt.

\section{Abbreviations}

IDDs: Iodine Deficiency Disorders

JHS: Junior High School

LEKMA: Ledwokuku krowor Municipal Assembly

OR: Odds Ratio

MICS: Multiple Indicator Cluster Survey

SPSS: Statistical Package for Social Sciences

UNICEF: United nations Children Educational Fund

WHO: World Health Organization

\section{Funding}


All activities that led to the writing of this manuscript were self-financed.

\section{Availability of Data}

All data supporting the conclusions of this article are in the manuscript.

\section{Authors Contribution}

JS was engaged in data collection, data curation, analysis and interpretation of data, drafting and reviewing of manuscript. PNG was involved in analysis and interpretation of data, reviewing of the manuscript. FS, was involved in data management, data analysis and reviewing of manuscript. CB was engaged in sample collection, data analysis as well as reviewing of manuscript. FNA was involved in data collection and reviewing of manuscript. BAA was involved in data collection, data analysis and drafting of manuscript. MSA was involved in data collection, analysis and interpretation and reviewing of manuscript. All authors approved of final version of the manuscript.

\section{Ethical Approval and Consent to Participate}

Ethical approval was given by the Scientific Board of Department of Nutrition and Food Science, University of Ghana. Study participants gave their written consents or thumb impression to participate. Permission was granted by the Municipal Assembly.

\section{Competing Interest}

Authors have no conflict of interest.

\section{REFERENCES}

[1] WHO. Global health risks: mortality and burden of disease attributable to selected major risks. Geneva, Switzerland: World Health Organization, 2009.

[2] WHO. Global Nutrition Policy Review: what does it take to scale up nutrition action? Geneva, Switzerland: World Health Organization, 2013

[3] Andersson M, Karumbunathan V, Zimmermann MB. Global iodine status in 2011 and trends over the past decade. J Nutr 2012; 142:744-50. 5.

[4] Asibey-Berko E., and Orraca-Tetteh R., eds. (2005). Proceedings of the National Workshop on Iodine
Deficiency Disorders in Ghana July 1994. Department of Nutrition and Food Science- University of Ghana, Legon, Accra.

[5] WHO. Global health risks: mortality and burden of disease attributable to selected major risks. Geneva, Switzerland: World Health Organization, 2009.

[6] Buxton, C. and Baguune, B. (2012). Knowledge and Practices of People in Bia District, Ghana, with Regard to Iodine Deficiency Disorders and Intake of Iodized Salt. Archives of Public Health, 70:5

[7] Ghana Demographic and Health Survey Report (GDHS). (2014). Ghana Statistical Service Accra, Ghana.

[8] Pearce E. N., Andersson M. \& Zimmermann M. B. (2013). Global iodine nutrition: where do we stand in 2013? Thyroid, 23(5), 523-528.

[9] Zimmermann M.B. (2009). Iodine Deficiency. Endocrine Reviews, Volume 30, Issue 4, 1 June 2009, Pages 376-408.

[10] David L. Simpong, Patrict Adu, Rashid Bashiru, Martin T. Morna, Francis A. Yeboah, Kafui Akpakpo and Richard K.D. Ephraim. 2016. Assessment of Iodine Status among Pregnant Women in a Rural Community in Ghana - A Cross Sectional Study. Archives of Public Health (2016) 74:8.

[11] Ahiadeke, C., Ackah, C., Aryeetey, R. and Acquah, A. (2012). Factors Influencing the Use of Adequately Salt in Ghana. African Journal of Food Science Vol. 6(3), Pp. 15, 58-64.

[12] Ghana Nutrition Profile. (2011). Overview of 2011 Ghana Nutrition Profiles Results. Ghana Health Service Nutrition Department and USAID/FANTA II, Retrieved 5th May 2016 from: https://www.fantaproject.org/sites/default/files/ resources/GhanaOverview-PROFILES-Feb2013.pdf

[13] Ghana Statistical Service, G. S. S. (2011). Ghana multiple indicator cluster survey with an enhanced malaria module and biomarker. Final Report.

[14] Ruel MT, Alderman H. Nutrition-sensitive interventions and programmes: how can they help to accelerate progress in improving maternal and child nutrition? Lancet 2013; 382:536-51.

[15] Stevens GA, Finucane MM, Paciorek CJ, et al. Trends in mild, moderate, and severe stunting and underweight, and progress towards MDG 1 in 141 developing countries: a systematic analysis of population representative data. Lancet 2012; 380:824-34.

[16] WHO. Global Nutrition Policy Review: what does it take to scale up nutrition action? Geneva, Switzerland: World Health Organization, 2013.

[17] WHO. Nutrition Guidance Expert Advisory Group (NUGAG) Micronutrients subgroup - terms of reference. Geneva, Switzerland: World Health Orgaization, 2010.

[18] Gorstein J, Sullivan KM, Parvanta I, Begin F. Indicators and methods for cross-sectional surveys of vitamin and mineral status of populations. Micronutrient Initiative (Ottawa) and Centers for Disease Control and Prevention (Atlanta), May 2007, pg 29).

[19] Takele L, Belachew T, Bekele T: Iodine concentration in salt 
at household and retail shop levels in Shebe Town, South West Ethiopia. East Af Med J 2003, 80(10):532-539)

[20] Charlton, K.E., Yeatman, H.R. and Houweling, F. (2010). Poor iodine Status and Knowledge Related to Iodine on the Eve of Mandatory Iodine Fortification in Australia. Asia Pac J. Clin. Nutr;19 (2):250-255.

[21] World Health Organization, United Nations Children's Fund, International Council for the Control of Iodine Deficiency Disorders. Assessment of iodine deficiency disorders and monitoring their elimination. A guide for programme managers. 3rd edn. Geneva, Switzerland: World Health Organization, 2007.

[22] Chirawurah D, Apanga S., \& Addah, J. (2015). Assessing iodized salt use in rural northern Ghana: a mixed method approach. Food and Public Health, 5(3), 70-76.

[23] Charterhouse. (2012). Dip-Stick Baseline Assessment Report: National Communication Campaign. Ghana Health Service and UNICEF Accra Ghana.

[24] Sandaresan, S., Pandav, C.S., Mannar, M.G.V. and Galvin, M. (2011). Summary Report Iodized Salt Coverage Study 2010 Conducted Across Eight States in India, Zamroodpur Community Centre New Dehli, Pp. 19-25

[25] UNICEF (2008). Sustainable Elimination of Iodine Deficiency: Progress since the 1990 World Summit for Children / UNICEF, New York, Pp. 1-31. 